\title{
iLnEMF
}

\section{The impact of an economic recession on erotic shops: A Consumer Qualitative Study}

\author{
Kamenidou Irene (Eirini) ${ }^{1}$, Vassilikopoulou Aikaterini ${ }^{2,}{ }^{*}$ Mamalis Spyridon ${ }^{1}$, and Stavrianea \\ Aikaterini $^{3}$ \\ ${ }^{1}$ International Hellenic University, Greece \\ ${ }^{2}$ Hellenic Open University, Greece \\ ${ }^{3}$ National Kapodistrian University, Greece
}

\begin{abstract}
This paper provides insights into consumer behavior towards erotic shops during an economic crisis. Specifically, it deals with the impact of a financial crisis on participants' visits to conventional and online erotic shops and to their relevant purchase behavior. It addresses three issues: 1. The impact of the economic crisis on visits to the erotic shops, 2 . The impact of the economic crisis on purchasing behavior from an erotic shop, and 3. The purchasing of, or intention to purchase, lower quality erotic products due to the economic crisis. Totally, 152 in-depth interviews were conducted. Results showed that participants experienced the impact of the crisis differently and had diverse visiting and purchase behavior depending on age, marital status, and profession. Based on the results, managerial implications are proposed
\end{abstract}

Keywords: economic crisis, consumer behavior, "erotic" shops, qualitative research, marketing communications

\section{Introduction}

Previous research shows that consumers become more rational about their purchasing behavior during times of economic stress (Ang, 2001; Ang et al., 2000; Gajewski, 1992; Kaytaz \& Gul, 2014; Mansoor and Jalal, 2011; Nistorescu \& Puiu, 2009; Priporas et al., 2015). An economic crisis affects salaries, and thus money concerns terminate or decrease spending on leisure or entertainment-related purchasing (Ang, 2001; Mansoor \& Jalal, 2011). Nistorescu and Puiu (2009) found that the financial crisis leads consumers away from purchasing premium products and forces them to purchase necessities.

After 2010, and the signing of the memorandum of understanding, Greece came under the surveillance of a protective mechanism. The country started to sink into a deep recession. Despite the harsh measures taken, Greece failed to improve its position in the international markets and signed a total of four memoranda (Kamenidou et al., 2020). These measures included salary cuts, cuts in pensions, and cuts in every aspect of Greek's economic life. In addition, an increase in tax levels and the implementation of austerity programs resulted in poverty indicators worsening rapidly (INE GSEE, 2014; Salourou, 2013). 


\section{i[C를}

Kent and Brown (2006) state that erotic retailing "is concerned with products and images that are sexually arousing, but not pornographic". Since the first erotic shop in 1962 (Uhse, 2014), erotic shops have spread all over the world. Although there are many consumer goods and services that are connected to erotism, from the consumer behavior perspective it has been rarely investigated in the past (Walthera \& Schoutenb, 2016).

In Greece, official statistics regarding "erotic"-related products and the "erotic" shop industry do not exist. According to fair organizer G. Chrysospathis' interview with Papachristou (2012), until 2010, about 300-400 "erotic" shops had opened only in the capital Athens, while after signing the Memorandum of Understanding (MoU), more than one half of the businesses closed.

On the other hand, according to the life history theory (LHT), when vital resources decrease (i.e., adverse conditions to future survival), amongst which is an extensive economic crisis (effecting their perception of future life conditions) individuals' preparedness to engage in sex increases (Griskevicius et al., 2011), also boosting the probability to visit a sex shop or purchase its products.

Thus, due to above contradictory matters, the following research questions (RQ) arose:

1. Do people during an economic crisis visit erotic shops?

2. Has an economic condition impact purchasing behavior from an erotic shop?

3. Do people due to the economic crisis intend to or purchase, lower quality "erotic" products?

Based on the above statements, this paper investigates consumers' behavior towards "erotic" shops in the period of the deep recession that Greece is experiencing. In particular, it addresses the following objectives:

1. Impact of the economic crisis on visits to "erotic" shops, answering RQ1.

2. Impact of the economic crisis on purchasing behavior from a "erotic" shop, answering RQ2.

3. The purchasing of, or intention to purchase, lower quality "erotic" products due to the economic crisis, answering RQ3.

This research attempts to close the following gaps in literature: It addresses an issue that is understudied from the consumer behavior perspective, even though "erotic" shops are considered as "big business". It also addresses the issue under economic constraints which to our knowledge has not been studied up to now.

It is pointed out that when referring to erotic shops and products, this paper does not refer to porn or uses of products. 


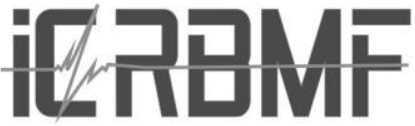

\section{Literature Review}

Carr and Taylor (2010, p.18), emphasize that even though the sex/erotic industry is a multibillion-dollar industry, the erotic shop as a business "is a relatively under-researched topic." As to erotic shop related issues, research has been realized on the legal issues/aspects of erotic shops or erotic toys (e.g., Hubbard, 2015; Stabile, 2013). In addition, studies have focused on the role of erotic shops in safe sex promotion, HIV prevention, and sex education (e.g., Godin et al., 2008; Reece et al., 2004). Other studies have centered on erotic products-related accessories, toys, and their use (e.g., Herbenick et al., 2015; Jozkowski et al., 2013). Also, research has looked at employees/ workers at "erotic"-shops (e.g., Hancock et al. 2015; Tyler, 2012); location/ geography (e.g., Coulmont \& Hubbard, 2010; Prior \& Crofts, 2012), and the history of erotic shops (e.g., Evans et al., 2010).

While the above studies are informative, few studies have focused on traditional or online erotic shops and consumer behavior (e.g., Attwood, 2005; Brown, 1998; Daneback et al., 2011; Evans et al., 2010; Fisher \& Barak,2000; Hefley, 2007; Kent \& Brown, 2006; Malina \& Schmidt,1997). These studies have undeniably contributed to the understanding of the subject; however, no studies have been found (to our knowledge) regarding customer behavior towards erotic shops during an economic crisis. Thus, a large gap in the theoretical and practical aspects of the subject remains.

Daneback et al. (2011) investigated consumer behavior in online erotic shops. They found that the purchasing of "erotic"-related products was associated with age, relationship status, sexual orientation, and nationality. Convenience was found to be the primary contributing factor in the consumers' decision to make their purchases via the internet.

Kent and Brown (2006) studied consumer behavior changes in British erotic shops from 1963 to 2003. Attwood (2005) investigated the social construction of the new female sexuality, examining the marketing of erotic products to women through content analysis of websites associated with four "erotic businesses". They found that these websites attempted to connect erotic-related products with fashion, modern lifestyle, youthfulness, pleasure, and self-care.

Kent (2005), when exploring erotic shops for women, employed a mixed-method approach (observation, content analysis of photographic archives of seven erotic shops, and an interview with a salesclerk of a UK "shop). According to the survey results, product design and the re-evaluation of the operation of erotic toys have significantly changed the attitudes and opinions of consumers, especially since 1990, due to the dynamic commercial presence of stores such as Ann Summers.

Malina and Schmidt (1997) investigated the characteristics of the services provided by female erotic shops, as well as the attitudes and perceptions of women using a case study in the British female store Sh! They found that divergent consumer behavior is transformed into legitimate hedonistic consumption. Customers do not only participate but also contribute to creating new products in the context of the novel exculpation of desires and the establishment of their sexual identity based on their values, beliefs, and attitudes. 


\section{it글}

\section{Methodology}

Given this study's exploratory nature and the limited prior research on this subject, marketing literature on consumer behavior suggests that qualitative research should be undertaken. Qualitative research uses a non-representative sample, and non-statistical methods are employed for the analysis of the results (Malhotra \& Peterson, 2006). This offers insights into the questions that address the way people think about this particular subject (Hair et al., 2007, p. 152).

For collecting the qualitative data, two waves of data collection were implemented, and a mixed-method approach. The first wave regards face-to-face in-depth interviews, particularly suitable for sensitive issues (Robson \& Foster, 1989), like sexual behavior. It was conducted from September to December 2016. The second wave was two years after (2018), and data was collected via asynchronous online interviews with an open-end questionnaire (Stavrianea et al., 2019). The first wave resulted in 48 interviews, while the second wave resulted in 104 participants. Participants were selected based on purposive sampling, i.e., choose participants using an important feature (Patton, 1990). In the current study, adults who have been sexually active were eligible to participate in the research. All interviewees were volunteers who agreed to participate in the study. Anonymity and confidentiality were ensured, and all participants were informed by the researchers that data collected will be used only for the purposes of the current research study. Totally 152 interviews were conducted during this two-wave data collection period.

Inductive or conventional content analysis was used to analyze the data since limited information exists on the specific topic, either as a theory or prior research (Hsieh \& Shannon, 2005). The researchers individually analyzed the data cross-sectional per question, developing a code sheet with the themes, codes, and phrases that emerged. Following, the results were compared, giving composite inter-judge reliability of $88.3 \%$, which is considered satisfactory (Kassarjian, 1977). Moreover, two experts (psychologists) were recruited to establish the validity of the category system and compared their codes and themes with the researchers.

\subsection{Sample Profile}

Regarding gender, males and females were almost equally represented (75 men and 77 women), ranging from 18 to 58 years old. They were divided into three groups: 18-25 (57.1\%), 26-35 years old (30.4\%) and 36+ (12.5\%). Referring to marital status, $123(80.9 \%)$ were single; $20(13.2 \%)$ were married, and $9(5.9 \%)$ were divorced/separated or widowed, while only 29 participants had children. As regards professional occupation, 56 (36.8\%) were employees (federal and private); 18 (11.9\%) were professionals; $3(2.0 \%)$ were on a pension, and $75(49.3 \%)$ were dependent on others (students, housewives and unemployed). 


\section{i[CR日F}

\section{Results}

\subsection{Impact of the economic crisis on visits to erotic shops}

Most participants stated that for them, the frequency of their visits had decreased significantly due to economic restraints:

"It has adversely affected me; wages are low, the money entering the house is a lot less, so it makes sense to cut such hobbies or habits. In essence, what is the point of visiting if you can't buy anything?" (C25, male, 24 years old).

"Yes, it has. I stopped going. I have now money only to spend for necessities" (C97, female, 49 years old).

"Yes, because there is no mood for sex" (C144, male 49 years old).

However, there were some participants, mainly the younger ones, who considered that the economic crisis had had no impact, or a small impact, on their visits to erotic shops:

"No, because looking doesn't hurt anyone" (C3, male, 21 years old).

On the other hand, the frequency of visiting online erotic shops seems unaffected by the crisis.

"My visits did not decrease due to the economic crisis, especially to an online sex shop. It doesn't cost anything to "get in" and look. No one can make you embarrassed because you can't buy anything. For me as a woman, an essential part of my personality is to go "strolling" and "window shopping" and I have not lost the opportunity to do so. Purchases, however, have become limited, which is reasonable since sex shops are not known for their low prices." (C116, female, 20 years old).

In addition, some participants asserted that their online visits increased.

"I don't go out often anymore. When I stay home, I surf the Net... what else to do? I visit two-three good sex shops almost every week. A few years ago, I would prefer to go out and drink some beers instead of surfing..." (C88, male, 28 years old).

Table 1 summarizes the key findings on the connection between visits to erotic shops and the economic recession. 
Table 1: Visits to erotic shops during economic crisis

\begin{tabular}{|l|l|}
\hline Physical erotic shops & Online erotic shops \\
\hline Visits decreased due to the crisis & Visits remained the same/ increased due to the crisis. \\
\hline Reasons: & $\underline{\text { Reasons: }}$ \\
Lack of money/ reduced income & Stay home/ go out less. \\
Lack of time & Feel good to have a look (for free) \\
Depression/ bad mood & Promotions \\
No mood/need for sex & \\
Perceived high prices & \\
\hline
\end{tabular}

Table 2 presents the visits to erotic shops based on demographic characteristics: gender, age, marital status, and occupation in frequencies. From table 2 it is evident that the vast majority of the females, the youngest age group, single and dependent were the most affected by the economic crisis as regards their visit to erotic shops.

Table 2: Visits to erotic shops based on demographic characteristics

\begin{tabular}{|l|c|c|}
\hline \multicolumn{1}{|c|}{ Demographic characteristic } & Yes & No \\
\hline Male & 40 & 25 \\
\hline Female & 75 & 25 \\
\hline $18-25$ & 62 & 11 \\
\hline $26-35$ & 35 & 1 \\
\hline $36+$ & 18 & 28 \\
\hline Single & 95 & 5 \\
\hline Married & 15 & 4 \\
\hline Divorced/widowed & 5 & 18 \\
\hline Employees & 38 & 4 \\
\hline Professionals & 14 & 0 \\
\hline On pension & 3 & 15 \\
\hline Dependent & 60 & \\
\hline
\end{tabular}




\section{it글}

\subsection{Impact of the economic crisis on erotic shops purchasing behavior}

Regarding their purchasing from erotic shops and compared to previous years or visits, the vast majority has reduced the amount of money spent on erotic-related products from erotic shops due to the economic crisis. This was more obvious in those who had a lower income, due to their jobs or to the money that their parents send to them (students), or those who had other priorities that had to be taken care of first (e.g., children). The amount spent in most cases dropped by more than 50\%:

"Of course it has had an impact because when you cannot cover your basic financial costs, you don't go around buying things for pleasure...... I don't purchase any more, so the rate of reduction is $100 \% "(\mathrm{C} 3$, male, 21 years old $)$.

"Yes, it has. It might not cost anything to take a look, but products from sex shops are very expensive. I have decreased my spending by more than 40\%" (C130, male).

"Regarding myself, I always wanted to buy a costume for my girlfriend, but prices were very high, and I didn't get to the point of purchasing one" (C13, male, 21 years old).

"The economic crisis has made me purchase products from another kind of sex shops... peddlers! Mostly sexy lingerie and erotic CDs that I cannot find on the internet. They do not say that they are peddler sex- shops, but in essence, they are....100\% reduction in spending from sex shops" (C152, male, 48 years old).

On the other hand, many considered that the crisis did not affect them at all because they did not visit erotic shops often or purchase anything from them; so, in essence, their behavior before and after was the same. A few though stated that it did not affect them very much, or at all, and that they kept on visiting and purchasing as before:

"Yes, it has affected me, but not so much, I am in a better economic situation compared to others" (C68, male, 21 years old).

"No. it hasn't affected me at all. I keep on visiting regularly, and that is the same for the products I buy. I believe that the pleasure of sex is paramount, so it should not be neglected. That is why I keep on visiting and purchasing products to keep my relationships interesting." (C120, female, 21).

Table 3 presents the impact of the economic crisis on erotic shops purchasing behavior based on demographic characteristics: gender, age, marital status, and occupation in frequencies. From table 3 it is evident that the vast majority of the females, the youngest age group, single and dependent were the most affected by the economic crisis as regards their visit to erotic shops. 
Table 3: Impact of the economic crisis on erotic shops purchasing behavior based on demographic characteristics

\begin{tabular}{|l|c|c|}
\hline \multicolumn{1}{|c|}{ Demographic characteristic } & Yes & No \\
\hline Male & 65 & 10 \\
\hline Female & 75 & 2 \\
\hline $18-25$ & 79 & 8 \\
\hline $26-35$ & 43 & 3 \\
\hline $36+$ & 18 & 1 \\
\hline Single & 116 & 7 \\
\hline Married & 18 & 2 \\
\hline Divorced/widowed & 6 & 3 \\
\hline Employees & 49 & 7 \\
\hline Professionals & 15 & 3 \\
\hline On pension & 3 & 0 \\
\hline Dependent & 73 & 2 \\
\hline
\end{tabular}

\subsection{The purchasing of, or intention to purchase, lower quality erotic products due to the economic crisis}

The significant majority of participants claimed that they would not buy lower quality erotic products, basically for safety reasons:

"I prefer not to buy anything than something that can hurt my partner or me during sex, with God knows what consequences, physical or emotional" (C142, female).

"No, it is better to buy things once a year than buy cheap no-name sex toys. That is what I do. I save my money, visit an erotic shop with my partner once a year and spend around 150 Euros. I will buy one or two things because products in erotic/sex shops are very expensive" (C150, male, 21 years old).

However, participants would appreciate some sales promotions or discounts.

"I always look for offers in online sex shops. But there are not many. Sure, I would have more chances to buy an erotic toy with $40 \%$ or $50 \%$ off" (C49, female, 38 years old).

"I look for special offers and discounts on everything these days! Well, I am not sure if I would buy [an erotic toy] but.. yes, I could buy it as a present if it were really cheap, or even 
for myself. Since these products are just for fun, discounts are a strong motivation..." (C71, female, 41 years old).

Table 4 presents the purchasing of, or intention to purchase, lower quality erotic products due to the economic crisis based on demographic characteristics: gender, age, marital status, and occupation in frequencies. From table 4 it is evident that the vast majority of the sample will not proceed in purchasing low quality erotic products due to the economic crisis.

Table 4: The purchasing of, or intention to purchase, lower quality erotic products due to the economic crisis based on demographic characteristics

\begin{tabular}{|l|c|c|}
\hline \multicolumn{1}{|c|}{ Demographic characteristic } & Yes (N) & No (N) \\
\hline Male & 72 & 3 \\
\hline Female & 77 & 0 \\
\hline $18-25$ & 85 & 3 \\
\hline $26-35$ & 46 & 0 \\
\hline $36+$ & 19 & 0 \\
\hline Single & 120 & 3 \\
\hline Married & 20 & 0 \\
\hline Divorced/widowed & 9 & 0 \\
\hline Employees & 56 & 0 \\
\hline Professionals & 18 & 0 \\
\hline On pension & 3 & 0 \\
\hline Dependent & 72 & 3 \\
\hline
\end{tabular}

\section{Discussion and Conclusions}

This study's basic aim was to investigate consumer purchasing behavior towards erotic shops during an economic downturn. This was realized through qualitative research, which investigated the impact of the economic crisis in visiting to and purchasing behavior towards erotic shops.

The analysis showed that participants experienced the economic crisis's impact in terms of visit and purchasing behavior towards an erotic shop differently and those significant differences were depending on age, marital status, and profession.

For younger subjects, visits to erotic shops were not affected since they believe that looking does not necessarily commit them to buy anything. Older and married participants have reduced the frequency of their visits to physical erotic shops because they feel uncomfortable since they cannot purchase anything. On the other hand, the frequency of visits to online erotic shops has not been affected by the economic crisis since anonymity exists, and no one is criticized for not purchasing. 


\section{itRenEF}

As for buying products from erotic shops, the majority of the participants have decreased the frequency of purchases and the amount of money they spend by $50 \%+$ compared to previous years. Therefore, the provision and communication of an effective website that can offer value to the users can become a significant advantage for these businesses (Shobeiri et al., 2018).

Previous research suggests that in economic recessions, consumers accept lower quality products (Gajewski, 1992) since they focus on price and not quality (Mansoor and Jalal, 2011). Moreover, they replace expensive products with cheaper ones where possible (Kaytaz \& Gul, 2014), or reduce product quantity and/or quality (Urbonavicius \& Pikturniene, 2010). With this concept in mind, participants were asked if they purchased or were willing to purchase lower quality but cheaper erotic products due to the economic crisis. Respondents answered that they are not willing to purchase any erotic toy or related accessories (excluding lingerie and erotic CDs) that are of lower quality, mainly for safety reasons. On the other hand, discounts or other sales promotions seem to be highly appreciated by the majority of respondents and should be key communication points to potential customers.

This study also revealed that consumers had changed their purchasing behavior due to the economic crisis' economic and psychological impact, in agreement with previous studies on the economic downturn's impact. Thus, erotic shops have to adjust to survive on a long-term basis. Erotic shops can benefit from this research's results by understanding how and whom they should target and adjust their prices in the current conditions. Accordingly, adequate communication, especially through digital media should be implemented by the businesses.

\section{Limitations and recommendations for further research}

This research has limitations that suggest possibilities for further research. The first limitation regards the nature of the study itself; it is qualitative in nature, so it focused exclusively on gaining depth of understanding. The second limitation refers to the sample of the study. Even though it is not considered small for qualitative research, the sample of this study cannot be considered representative of all Greek consumer behavior during the economic crisis. Lastly, future studies should include quantitative measures to examine the validity of the current findings. 


\section{iERBMF}

\section{References}

Ang, S.H, Leong, S.M. and Kotler, P. (2000). The Asian apocalypse: crisis marketing for consumers and businesses, Long Range Planning, vol. 33 no. 1, pp. 97-119.

Ang, S,H. (2001). Crisis marketing: a comparison across economic scenarios, International Business Review, vol. 10 no. 3, pp. 263-284.

Attwood, F. (2005). Fashion and passion: marketing sex to women, Sexualities, vol. 8 no. 4, pp. 392-406.

Brown, S. (1998). Romancing the market sex, shopping and subjective personal introspection, Journal of Marketing Management, vol. 14 no. 7, pp. 783-798.

Carr, N. and Taylor, S. (2010). Sex Shops of the 21st Century: Are 'you' being Served? In Carr, N. and Poria, Y. (eds). Sex and the sexual during people's leisure and tourism experiences. Newcastle upon Tyne, UK: Cambridge Scholars Publishing, pp. 17-34.

Coulmont, B. and Hubbard, P. (2010). Consuming sex: socio-legal shifts in the space and place of sex shops, Journal of Law and Society, vol. 37 no. 1, pp. 189-209.

Daneback K, Mansson, S,A. and Ross MW. (2011). Online sex shops: Purchasing sexual merchandise on the internet, International Journal of Sexual Health, vol. 23 no. 2, pp. 102110

Evans A., Riley, S. and Shankar, A. (2010). Postfeminist heterotopias: negotiating 'safe' and 'seedy' in the British sex shop space, European Journal of Women's Studies, vol. 17 no. 3, pp. 211-229.

Fisher, W. and Barak, A. (2000). Online sex shops: phenomenological, and ideological perspectives on internet sexuality, Cyber Psychology \& Behavior, vol. 3, pp. 575-589.

Gajewski, S. (1992). Consumer behavior in economics of shortage, Journal of Business Research, vol. 24 no. 1, pp. 5-10.

Griskevicius, V. G., Tybur, J. M., Delton, A. W. and Robertson, T. E. (2011). The influence of mortality and socioeconomic status on preferences for risk and delayed rewards: A life history theory approach, Journal of Personality and Social Psychology, vol. 100, pp. $1015-1026$

Godin, G., Naccache, H., Cote, F., Leclerc, R., Frechette, M. and Alary, M. (2008). Promotion of safe sex: evaluation of a community-level intervention programme in gay bars, saunas and sex shops, Health Education Research, vol. 23 no. 2, pp. 287-297.

Hair, J.F, Money, A, Page, M. and Samouel, P. (2007). Research Methods for Business, Chichester, UK: John Wiley \& Sons.

Hancock, P., Sullivan, K. and Tyler, M. (2015). A touch too much: negotiating masculinity, propriety and proximity in intimate labour, Organization Studies, vol. 36 no. 12, pp. 17151739.

Hefley, K. (2007). Stigma management of male and female customers to a non-urban adult novelty store, Deviant Behavior, vol. 28 no. 1, pp. 79-109. 


\section{iE 2 碴MF}

Herbenick, D., Barnhart, K.J, Beavers, K. and Benge, S. (2015). Vibrators and other sex toys are commonly recommended to patients, but does size matter? Dimensions of commonly sold products, The Journal of Sexual Medicine, vol. 12 no. 3, pp. 641-645.

Hsieh, H.F. and Shannon, S.E. (2005). Three approaches to qualitative content analysis, Qualitative Health Research, vol. 15 no. 9, pp. 1277-1288.

Hubbard, P. (2015). Law, sex and the city: regulating sexual entertainment venues in England and Wales, International Journal of Law in the Built Environment, vol. 7 no. 1, pp. 5-20.

INE GSEE (2014). Poverty indicators in Greece worsened rapidly with the onset of the economic crisis and the implementation of austerity programs [Online, In Greek]. Available: http://ineobservatory.gr/i-diktes-ftochias-stin-ellada-epidinothikan-ragdea-metin-emfanisi-tis-ikonomikis-krisis-ke-tin-efarmogi-ton-programmaton-litotitas/ [accessed on 17 March 2015]

Jozkowski, K.N., Herbenick, D., Schick, V., Reece, M., Sanders, S.A and Fortenberry, J.D. (2013). Women's perceptions about lubricant use and vaginal wetness during sexual activities, The Journal of Sexual Medicine, vol. 10 no. 2, pp. 484-492.

Kassarjian, H.H. (1977). Content analysis in consumer research, Journal of Consumer Research, vol. 4 no. 1, pp. 8-18.

Kaytaz, M. and Gul, M.C. (2014). Consumer response to economic crisis and lessons for marketers: The Turkish experience, Journal of Business Research, vol. 67 no. 1, pp. 27012706.

Kent, T. and Brown, R. (2006). Erotic retailing in the UK (1963-2003). The view from the marketing mix, Journal of Management History, vol. 12 no. 2, pp. 199-211.

Kent T. (2005). Ethical perspectives on the erotic in retailing, Qualitative Market Research: An International Journal, vol. 8 no. 4, pp. 430 - 439.

Malhotra, N.K. and Peterson, N. (2006). Basic Marketing Research, Englewood Cliffs, NJ: Prentice-Hall.

Malina, D. and Schmidt, R. (1997). It's business doing pleasure with you: Sh! A women's sex shop case, Marketing Intelligence \& Planning, vol. 15 no. 7, pp. 352-360.

Mansoor, D. and Jalal, A. (2011). The global business crisis and consumer behavior: Kingdom of Bahrain as a case study, International Journal of Business and Management, vol. 6 no. 1, pp. 104-115.

Nistorescu, T. and Puiu, S. (2009). Marketing strategies used in crisis-case study. MPRA paper, 17743 [Online]. Available: http://mpra.ub.uni-muenchen.de/17743/ [accessed on 6 August 2016]

Papachristou, H. (2012). Greek sex industry battered by economic storm [Online]. Available: http://uk.reuters.com/article/2012/05/28/uk-greece-sex idUKLNE84R01D20120528 [accessed on 16 August 2018]

Patton, M.Q. (1990). Qualitative Evaluation and Research Methods, 2nd ed., Newbury Park, CA: Sage. 


\section{it글}

Prior, J. and Crofts, P. (2012). Effects of sex premises on neighbourhoods: Residents, local planning and the geographies of a controversial land use, New Zealand Geographer, vol. 68 no. 2, pp. 130-140.

Priporas, C.V, Kamenidou, I, Kapoulas, A. and Papadopoulou, F. (2015). Counterfeit purchase typologies during an economic crisis, European Business Review, vol. 27 no. 1, pp. 2-16.

Reece, M., Herbenick, D. and Sherwood- Puzzello, C. (2004). Sexual health promotion and adult retail stores, Journal of Sex Research, vol. 41 no. 2, pp. 173-180.

Robson, S. and Foster, A. (1989). Qualitative Research in Action, London, UK: Hodder and Stoughton.

Salourou, R. (2013). Under the poverty level almost 4 million Greeks [Online]. Available: http://www.capital.gr/NewsTheme.asp?id=1729305 [accessed on 7 May 2019].

Stabile, E. (2013). Commentary: getting the government in bed: how to regulate the sex-toy industry, Berkeley Journal of Gender, Law \& Justice, vol. 28 no. 2, pp. 161-184.

Shobeiri, S., Mazaheri, E. and Laroche, M. (2018). Creating the right customer experience online: The influence of culture, Journal of Marketing Communications, vol. 24 no. 3, pp. 270-290.

Stavrianea A., Bara EZ. and Mamalis S. (2019). Reasons for Using Daily Deal Sites. In: Kavoura A., Kefallonitis E. and Giovanis A. (eds) Strategic Innovative Marketing and Tourism. Springer Proceedings in Business and Economics. Springer, Cham. https://doi.org/10.1007/978-3-030-12453-3 75

Tyler, M. (2012). Working in the other Square Mile: performing and placing sexualized labour in Soho's sex shops, Work, Employment \& Society, vol. 26 no. 6, pp. 899-917.

Uhse, B. (2014). Beate Uhse The Story [Online]. Available: http://www.beateuhse.ag/index.php/the-story.html [accessed on 16 August 2015]

Urbonavicius, S. and Pikturniene, I. (2010). Consumers in the face of economic crisis: evidence from two generations in Lithuania, Economics \& Management, vol. 15, pp. 827835.

Walthera, L. and Schoutenb, J.W. (2016). Next stop, Pleasure Town: Identity transformation and women's erotic consumption, Journal of Business Research, vol. 69 no. 1, pp. 273283. 